\title{
Developing Mid-Range Theories for the Maturation of Nursing Care in Colombia
}

Janice M. Morse

https://orcid.org/0000-0002-9017-1940 Distinguished Emerita, University of Utah, College of Nursing, United States of America; Emerita, University of Alberta, Canada. janice.morse@nurs.utah.edu

DOI: 10.5294/aqui.2021.21.4.6

To reference this article / para citar este artículo / Para citar este artigo

Morse JM. Developing Mid-Range Theories for the Maturation of Nursing Care in Colombia. Aquichan. 2021;21(4):e2146 DOI: https://doi.org/10.5294/aqui.2021.21.4.6 
Theme: Epistemology.

Contribution to the discipline: Mid-range theories target specific patient problems and enable the identification of nursing interventions, thus enhance patient care. By identifying the patient's psychosocial problem(s) and selecting from the compendium of related concepts, nurses may then select a mid-range theory as a therapeutic strategy, thereby systematically changing the patient's course of illness. 


\section{Abstract}

Nursing theory has evolved since the 1960 , from conceptual models to concept analysis to mid-range theories. Mid-range theories are developed primarily for qualitative research, to target patient problems, to respond to patient needs, to identify interventions and the changing patterns of patient care. These mid-range theories cluster in various patterns to provide valid, coherent, and significant interventions. Examples of programs that have dramatically impacted our understanding of nursing and patient care are presented. Thus, by developing and implementing the findings of midrange theories, nursing care matures, and the standards advance.

\section{Keywords (Source: DeCS)}

Nursing theories; nursing care; knowledge development;

research; nursing. 


\section{Desarrollo de las teorías de rango medio para la maduración de la atención de enfermería en Colombia}

\section{Resumen}

La teoría de enfermería ha venido evolucionando a partir de la década de 1960, desde los modelos conceptuales, pasando por el análisis de conceptos, hasta las teorías de rango medio. Las teorías de rango medio se desarrollan principalmente para realizar investigación cualitativa, enfocarse en los problemas del paciente, responder a las necesidades del paciente, identificar intervenciones y los patrones cambiantes de la atención al paciente. Estas teorías de rango medio se agrupan en varios patrones para brindar intervenciones válidas, coherentes y significativas. En este artículo, se presentan ejemplos de programas que han tenido un gran impacto en nuestra comprensión de la enfermería y el cuidado del paciente. Así, al desarrollar e implementar los hallazgos de las teorías de rango medio, la atención de enfermería madura y los estándares avanzan.

\section{Palabra clave (Fuente: DeCS)}

Teoría de enfermería; atención de enfermería; mejora; conocimiento; investigación; enfermería. 


\section{Desenvolvimento das teorias de médio alcance para o progresso da atenção de enfermagem na Colômbia}

\section{Resumo}

A teoria de enfermagem vem evoluindo desde a década de 1960, dos modelos conceituais, passando pela análise de conceitos, até as teorias de médio alcance. As teorias de médio alcance são desenvolvidas principalmente para realizar pesquisa qualitativa, para focar nos problemas do paciente, atender às necessidades do paciente, identificar intervenções e padrões oscilantes da atenção ao paciente. Essas teorias são agrupadas em vários parâmetros para oferecer intervenções válidas, coerentes e significativas. Neste artigo, são apresentados exemplos de programas que vêm tendo grande impacto em nossa compreensão da enfermagem e no cuidado do paciente. Assim, ao desenvolver e implementar os achados das teorias de médio alcance, a atenção de enfermagem progride e os parâmetros avançam.

\section{Palavras-Chave (Fonte: DeCs)}

Teoria de enfermagem; cuidados de enfermagem; conhecimento; pesquisa; enfermagem. 
In 2008, I visited the Universidad Nacional de Colombia, Bogotá, and was amazed at the development and utilization of nursing theory in patient care. Further, the integration of nursing theory/ frameworks into nursing research in Colombia is clear in Aquichan, where most research articles have used clinically relevant nursing frameworks, in particular, those developed by Dorothea Orem (1) and Callista Roy (2).

Nursing is entering another transitional wave: that of the development and application of mid-range theories. These theories differ from the conceptual models, as defined by Fawcett and DeSanoto-Madeya (3), which are used for the nursing care organization at the unit and institutional level and are not necessarily under the rubric of a conceptual model. Yet they work in a complementary manner with those conceptual models described by (3) to provide nurses with the tools for an individual's patient care, assessment, and interventions, according to the identified individual patient's problem(s), but they are not restricted to the narrow definition of nursing concepts.

The purpose of theories within and for nursing has much been discussed in the nursing literature and changed over time. First, and most influential, was the rise of nursing theories, primarily in the middle of the last Century, when nursing was struggling to become a profession in its own right. Nursing theories, largely developed in the 1960 s and 1970s, were theories of broad scope that delineated nursing practice (3). The most frequently cited conceptual models of these nursing theories are: Johnson's Behavioral System Model, King's Conceptual System, Levine's Conservation Model, Neuman's Systems Model, Orem's Self-Care Framework, Rogers' Science of Unitary Human Beings, and Roy's Adaptation Model (4). But in our haste to become a profession, we forgot that theories are a facilitating tool, and we are "masters" controlling such theories intended to facilitate our work. Thus, we previously molded our perspective according to the theory we selected to focus all of our care. It is a concern that some nursing schools dictate that, to be considered nursing, research must contain a nursing conceptual model (5). This often forced an artificial fit, for the selected model may have been too abstract for the proposed project'. Further, such an approach restricted the nursing perspective of research, the use of such research clinically, and ultimately the creativity of nursing research in our rapidly changing contexts of care, or was an add-on placed in the research to meet the requirement than to facilitate the research. Yet Fawcett insists that mid-range theories must be couched within conceptual models to be considered nursing research (5).

The second movement (for two decades from the 1990s) was the identification of concepts critical for patient care. Concept analysis may use the literature and reflexive qualitative inquiry to ex-

1 "The propositions of a conceptual model are so abstract and general that they are not amenable to direct empirical observation or test" (3, p13). 
plore ways the concepts are used and even interview data to verify the emerging conceptualizations of these concepts (6). While the research is generalizable, the theoretical structure remains basic and with the conceptual components and the interaction of these components integrated into the theory. Researchers actively incorporated concepts from other disciplines and contexts into nursing when appropriate, and this research further defined and enriched our understanding of nursing and contributed to the development of mid-range theories.

The third and present phase in our professional evolution, commencing about the mid-190os, is the construction and utilization of mid-range theories ${ }^{2}$. These mid-range theories, largely developed from or initiated by qualitative inquiry, are at various levels of development and scope and directly targeted towards specific patient problems and concerns, nursing interventions, and patient care outcomes. Mid-range theories may address different levels of specificity, for instance, from the microanalytic descriptions of interactions, of emotional responsiveness, touch, facial expressions, and dialogue to abstract ideas that jar us out of our routine perspectives.

In this article, I strongly suggest nursing recognize this shift to the pragmatic definitions of mid-range theory and move beyond the focus of conceptual models. These qualitatively-derived mid-range theories are primarily developed from qualitative research methods that directly use interviews and observations of patients, caregiving situations from nurses, families, and communities. Such qualitative research provides the tools to recognize patterns in patient states, needs, and abilities/disabilities. Qualitative research provides descriptions of interventions and modes of interactions that are comforting, therapeutic, and may even be harmful. Qualitative research findings are pragmatic, recognizable, and readily integrated into nursing care. Qualitative research provides us with the tools to evaluate patient conditions and even enhance patient access, aand the administration of care. Qualitative research may be prescriptive in its identification care problems and solutions and is generalizable through its links to concepts and theories. Qualitative research is solid and complete in itself 3 .

Nursing research must develop-and implement-these more specific, targeted mid-range theories to benefit patient care. Even though Fawcett agrees that "all nursing research may be considered a middle range theory" (4; see also 3 p17), astonishingly, Fawcett states that "shared theories"-mid-range theories using concepts developed in other disciplines (such as social support in social psychology) - do not advance our discipline "as much as nurse-specific theories" $(4, \mathrm{p} 4)$. To devalue, ignore or exclude theories encom-

2 Merton (25) describes this level of theory a "middle-range" theory, but this term has been abbreviated to the less pedantic term, 'mid-range.'

3 Quantitative verification is unnecessary for strong qualitative inquiry, just as it is often unnecessary for qualitative inquiry to supplement quantitative work. It may do so with mixed methods design, but it is not necessary. 
passing concepts inherent in our humanness is absurd ${ }^{45}$. It is time to move nursing research to its optimal level.

Thus, the question remains, how do we determine the most useful, valid, and generalizable research for the clinical area? More importantly, how do we formally transfer/implement these results clinically and across perceived ability/disability, gender, age, and cultural boundaries in various patient populations? Moreover, who is responsible for conducting and implementing this research?

\section{The Scope of Mid-Range Theories}

Mid-range theories explore nursing and the context from the most descriptive level to the most abstract, using a myriad of sources of data and a host of qualitative (and some quantitative) methods. The methodological goal is to develop a theory applicable to patient care that provides in-depth insight into patient problems, nursing interventions, and outcomes. A valuable way to categorize these "types" of mid-range theories follows.

Level 1, As descriptive: The most descriptive level of mid-range theories is studies of microanalytic processes that provide insight into what is actually occurring. These are studies of observable interactions, of emotional responsiveness, of touch, facial expressions, and of dialogue. They are basic studies that may include interview and observational data and even video recordings. Examples are the use and meaning of touch in patients with cancer (7) and comforting strategies during nasogastric tube insertions (8).

Level 2, AS exploration of concepts: The next level of abstraction is studies targeted toward the role, function, and even the utilization of concepts commonly occurring in the patients' experiences of illness and treatments. These analyses may use the literature and reflexive inquiry exploring ways the concepts are used and even interview data to verify the emerging conceptualizations of these concepts. While the research is generalizable, the theoretical structure remains basic and focused on the conceptual components. Such research may be an examination of hope to determine the structure of hope in various contexts (9) or the use of a frame or scaffold that data fills inductively (see, for instance, the use of resilience (10)).

\footnotetext{
4 It is not clear why Fawcett (4) targeted several of these concepts. Her own criteria is that concepts must be derived from nursing, yet most of the theories in this list include concepts that are not derived from nursing, including some critical to nursing, such as empathy, chronic sorrow, and even comfort.

5 Consider the origin of conceptual models: Fawcett and DeSanoto-Madeya write "They evolve(d) from empirical observations and intuitive insights of scholars or from deductions that creatively combine ideas from several fields of inquiry" (3 p13). Of greater concern, they continue "A conceptual model is inductively developed when generalizations about specific observations are formulated in specific situations are seen as examples of other more general events" (3 p13]. Yet Fawcett and DeSanoto-Madeya propose that "shared theories do not advance our discipline."
} 
Level 3, As the identification of trajectories: The third level is the identification of trajectories explicating patient experiences over time (11). Methods, such as grounded theory, enable the identification of stages and phases of responses and the changing dynamic and interactions of relevant concepts as the patients move through the illness. These trajectories at this level of development, are usually particular to one patient group, explicating the course of recovery or decline, patients with particular needs or problems; others may identify the course of the recovery. Some of these mid-range theories are general and may be used to conceptualize and organize minor concepts within their frame; many will identify nursing therapies that mitigate patient problems or facilitate, ease, and relieve discomfort. Qualitative documentation of any interventions may be used for the development and evaluation of these mid-range theories.

Level 4: Increasing scope: The fourth level consists of studies of broader scope that may be linked, or a comparative analysis of studies that explore the same experiences or concepts in different participant groups, in different situations; research that is seeking similar (or disparate) patterns, comparing patient responses, the occurrences of similar concepts in different contexts, or variations/ similarities of patient groups. This research is still at the developmental/exploratory stage, but the increasing evidence obtained from separate studies builds credence, validity, and certainty into the research program. Increasing emphasis is placed on the identification and efficacy of interventions. Emerging concepts are linked with the literature; the research is increasingly developed as conceptual and abstract, and mid-range theories, from the linking of concepts, are developed from the linking of concepts. An example is the development of the Praxis Theory of Comfort and Comforting from the synthesis of Level 1 descriptive studies of touch, presence, and interaction such as talking through (12).

Level 5, Multiple overlapping projects: Finally, Level 5 is solid individual qualitative studies, conducted as individual projects using different methods but within a cohesive topic. These projects are linked by the same general topic conducted in various stages of the disease process, in different patient age groups, in different illness experiences, developing and increasing our understanding of the concepts and confirming the theory. These projects may have been developed over time by a single investigator or team and consist of multiple qualitative studies conceptually linked to increasing understanding of the depth and scope of the topic. These qualitative research programs are powerful, pragmatic, significant, and generalizable. The findings are valid, rigorous, impactful, and, importantly, do not require quantitative validation, but quantitative methods may be used, for instance, to develop measure instruments. It is this research that now provides therapeutic strategies, is implemented as standard practice, directs our profession, and provides the tools that will make nursing, nursing ${ }^{6}$. Examples of this last phase are re- 
search programs conducted using multiple methods. The first is a multiple method research program developed by Canadians Judith Wuest, Marilyn Ford-Gilboe, Colleen Varcoe, and their colleagues. Using a program of multiple methods, they have developed a midrange theory as a basis for instrument and/ in which they used or intervention development and testing:

Study 1: Wuest et al. developed a grounded theory of health promotion in the process of leaving an abusive partner $(13,14)$.

Study 2: A four-year longitudinal quantitative study to capture the trajectory of women's health after leaving $(15,16)$.

Study 3: Used strategies of theoretical sampling and constant comparison of quantitative findings to further develop the grounded theory, to develop the Intervention for Health Enhancement after Leaving (iHEAL) $(17,18)$.

Study 4: Feasibility studies of the iHEAL (19).

Study 5: In process. Researchers are presently conducting a randomized control trial testing the intervention in three Canadian provinces (20).

Downloading all these studies and following the researcher's development of the project is an excellent way to appreciate the increasing abstraction and significance of a research program.

A second approach is to develop a cluster of qualitative studies to determine the scope of a phenomenon. Once completed, they are placed horizontally, linked by common concepts (rather like a puzzle). This method, theoretical cohesion, has been used by Beck to explore traumatic childbirth (21) and by Morse to explore the concept of enduring (22). In this way, you are developing Theoretical Coalescence model $(21,22)$, from what Dickoff and James (23) described as a "theory of theories."

\section{Developing these Methods for the Colombian Nursing Context}

How can these midrange theories be evaluated and used or modified, or redeveloped for the cultural context in Colombian or other South American countries? How can these results be clinically transferred to different patient populations? Are these mid-range theories specific, transferrable, or must we develop our own?

The first task of conducting solid single studies is already attained and are published in Aquichan and internationally. As noted above, these Level 1 descriptive studies may not be ready for implemen-

label smoothing to develop a published model, and as such, they are not as powerful and do not expand the concept. 
tation as a mid-range theory, as the content may be too specific. Nevertheless, they sensitize our clinical observation, which may provide an important foundation for identifying and analyzing more complex phenomena and further research. Further, as you obtain results, researchers must carefully compare their results to the other studies on the same topic conducted elsewhere. Ask: Are the result the same? Similar or different? Why? Are these procedural or structural differences in the provision of care? Or cultural differences? Differences within this institution, or more generally in Colombia? Even asking such questions may trigger the next project or give you confidence in your practice.

Nevertheless, all studies must be conducted with caution and care. Avoid studies with inadequate data (too small a sample or limitations in recruiting) or that have not been developed theoretically?. If your study "holds up," is consistent with the external study, and has developed an intervention, then apply the findings, and if appropriate, conduct an evaluation study. Furthermore, if you find similarities or differences, compare these in your published research.

\section{The Last Word}

This plea for the maturation of research, the utilization of qualitative inquiry, and the development of mid-range theory directly applicable to your clinical practice. From the above, we can see that qualitative inquiry is much more than a study of "the patient experience" (24); it provides a means for documenting the minute actions within the nurse-patient interaction; to identify the subjective, responsive components of care. It provides us with the means to "read" non-verbal patient behavior; to evaluate the efficacy of our interventions. It enables us to develop theories that recognize and predict patient behaviors, meet patient needs, and provide interventions. It is an essential and vital part of the development of nursing, one that systematically may change the patient's course of illness. As our knowledge base for nursing is continually evolving, the responsibility for developing safe and effective care is in your hands.

Conflicts of interest: The author declares no interest conflict.

7 Perhaps the research has not used a method, has restricted their study to the use of a strategy (such as thematic analysis), and not developed the themes. Even the labels of each theme may only be a phrase taken from a quotation. This research in incomplete, not conceptually or theoretically developed, not replicable, and not implementable. 
1. Denyes MJ, Orem DE, Bekel G. Self-care: A foundational science. Nurs Sci Q. 2001;14(1):48-54. DOI: https://doi. org/10.1177/089431840101400113

2. Roy C. Research based on the Roy adaptation model: Last 25 years. Nurs Sci Q. 2011;24(4):312-20. DOI: https://doi. org/10.1177/0894318411419218

3. Fawcett J, DeSanoto-Madeya S. Contemporary Nursing Knowledge: Analysis and evaluation of nursing models and theories. 3rd ed. Philadelphia: F. A. Davis; 2013.

4. Fawcett J. Middle range nursing theories are necessary for the advancement of the discipline. Aquichan. 2005;5(1):32-43. Available from https://aquichan.unisabana.edu.co/index.php/ aquichan/article/view/57

5. Fawcett J. Using the Roy adaptation model to guide research and/or practice: construction of Conceptual-TheoreticalEmpirical systems of knowledge. Aquichan. 2009;9(3):297-306. Available from: https://aquichan.unisabana.edu.co/index.php/ aquichan/article/view/1527

6. Morse JM. Analyzing and Conceptualizing the Theoretical Basis of Nursing. New York: Springer; 2017. DOI: https://doi. org/10.1891/9780826161024

7. Bottorff JL. The use and meaning of touch in caring for patients with cancer. Oncol Nurs Forum. 1993;20(10):1531-1538. Available from: https://pubmed.ncbi.nlm.nih.gov/8278279/

8. Penrod J, Morse JM, Wilson S. Comforting strategies used during nasogastric tube insertion. J Clin Nurs. 1999;8(1):31-8. DOI: https://doi.org/10.1046/j.1365-2702.1999.00229.x

9. Morse JM, Doberneck B. Delineating the concept of hope. J Nurs Scholarsh. 1995;27(4):277-85. DOI: https://doi. org/10.1111/j.1547-5069.1995.tboo888.x

10. Morse JM, Kent-Marvick J, Barry LA, Harvey J, Okang EN Rudd EA, Wang CY, Williams MR. Developing the resilience framework for nursing and healthcare. Glob Qual Nurs Res. 2021;8:1-21. DOI: https://doi.org/10.1177/23333936211005475

11. Vann-Ward T, Morse JM, Charmaz K. Preserving self: Theorizing the social and psychological processes of living with Parkinson disease. Qual Health Res. 2017;27(7):964-82. DOI: https://doi. org/10.1177/1049732317707494

12. Morse JM. Toward Understanding Comfort and Comforting. In Analyzing and Conceptualizing the Theoretical Basis of Nursing. New York: Springer; 2017.

13. Wuest J, Ford-Gilboe M, Merritt-Gray M, Berman H. Intrusion: the central problem for family health promotion among children and single mothers after leaving an abusive partner. Qual Health Res.2003;13(5):597-622. DOI: https://doi. org/10.1177/1049732303013005002

14. Ford-Gilboe M, Wuest J, Merritt-Gray M. Strengthening capacity to limit intrusion: Theorizing family health promotion in the aftermath of woman abuse. Qual Health Res. 2005;15(4):477501. DOI: https://doi.org/10.1177/1049732305274590

15. Ford-Gilboe M, Wuest J, Varcoe C, Davies L, Merritt-Gray M, Hammerton J, Wilk P, Campbell J. Modelling the effects of intimate partner violence and access to resources on women's health in the early years after leaving an abusive partner. Soc Sci Med. 2009;68(6):1021-1029. DOI: https://doi.org/10.1016/j. socscimed.2009.01.003

16. Scott-Storey KA, Hodgins M, Wuest J. Modeling lifetime abuse and cardiovascular disease risk among women. BMC Cardiovasc Disord. 2019 Dec;19(1):1-4. DOI: https://doi.org/10.1186/s12872019-1196-y

17. Ford-Gilboe M, Merritt-Gray M, Varcoe C, Wuest J. A theorybased primary health care intervention for women who have left abusive partners. ANS Adv Nurs Sci. 2011;34(3):198-214. DOI: https://doi.org/10.1097/ANS.ob013e3182228cdc

18. Wuest J, Ford-Gilboe M, Merritt-Gray M, Varcoe C. Exemplar: Building on "Grab," Attending to "Fit," and Being Prepared to "Modify": How Grounded Theory "Works" to Guide a Health Intervention for Abused Women. In: Morse JM, Bowers BJ, Charmaz K, Clarke AE, Corbin J, Porr CJ, Noerager Stern P, editors. Developing Grounded Theory. NY: Routledge; 2021. p.90-107. DOI: https://doi.org/10.4324/9781315169170-8

19. Wuest J, Merritt-Gray M, Dubé N, Hodgins M, Malcolm J, Majerovich J, Scott-Storey K, Ford-Gilboe M, Varcoe C. The process, outcomes, and challenges of feasibility studies conducted in partnership with stakeholders; A health intervention for women survivors of intimate partner violence. Res Nurs Health. 2015;38(1):82-96. DOI: https://doi.org/10.1002/nur.21636

20. Ford-Gilboe M. iHEAL Trial: Effectiveness of a health promotion intervention for women who have experienced intimate partner violence. U.S. National Library of Medicine; 2021. Available from: https://clinicaltrials.gov/ct2/show/NCT03573778

21. Beck CT. Middle range theory of traumatic childbirth: The everwidening ripple effect. Glob Qual Nurs Res. 2015. DOI: https:// doi.org/10.1177/2333393615575313

22. Morse JM. Theoretical coalescence: a method to develop qualitative theory: the example of enduring. Nurs Res. 2018;67(2):177-187. DOI: https://doi.org/10.1097/ NNR.0000000000000263

23. Dickoff J, James P. A theory of theories: A position paper. Nurs Res. 1968;17(3):197-203. DOI: https://doi.org/10.1097/00006199196805000-00004

24. Fawcett J. Tendencias de investigación en enfermería. Aquichan. 2014;14(3):289-93. DOI: https://doi.org/10.5294/aqui.2014.14.3.1

25. Merton RK. On sociological theories of the middle range; 1949 Available from: http://www.csun.edu/ snk1966/Robert\%20 K\%20Merton\%20-\%20On\%20Sociological\%20Theories\%20 of $\% 20$ the $\% 20$ Middle\%2oRange.pdf 